Session 1-3

\title{
Home Energy Conservation Audits, A Service Learning Experience For Industrial Technology Students
}

\author{
G.H. Massiha \\ Department of Industrial Technology \\ University of Louisiana at Lafayette
}

\begin{abstract}
The goal of this project is to conduct testing and community education in the area of home energy conservation and energy reduction to Louisiana homeowners. In the aftermath of hurricanes Katrina and Rita, rebuilding and repairing of damaged homes located in the areas devastated by the hurricanes happened so fast that many home owners may have to spend more for energy usage than before due to use of low standard construction material and inadequate financial situations.

In addition, there are many people who want to save energy but cannot afford to build an energy efficient home. Fortunately, there are many no-cost and low cost practices that can help everyone reduce energy waste and save energy dollars. Students in the construction course in Industrial Technology Department at University of Louisiana at Lafayette conduct energy surveys on houses and the data is disseminated to educate homeowners on energy guide labels, appliance energy use, and general energy conservation. This project concentrates on the year round energy consumption that occurs in the average home. The project results are shared with the home owners whose houses were tested.

Faculty involved in this project conduct presentations and workshops during the Spring of 2008 and 2009 Acadiana Home Builders Shows that will take place in the Convention Center in Lafayette. Student participants assist in these presentations and distribute handout on how to reduce energy consumption and improve their energy usage habits. This project ensures a large pool of well-trained students who will be available to enter both the energy and construction sectors. This project is currently at its infancy stage. In this presentation a general discussion of the project and students involvement will be presented.
\end{abstract}

